\title{
Correction to: Predicting Arabic word reading: A cross-classified generalized random-effects analysis showing the critical role of morphology
}

\author{
Sana Tibi ${ }^{1} \cdot$ Ashley A. Edwards ${ }^{2} \cdot$ Christopher Schatschneider $^{2} \cdot$ John R. Kirby $^{3}$ \\ Published online: 8 July 2020 \\ (C) The International Dyslexia Association 2020
}

\section{Correction to: Annals of Dyslexia \\ https://doi.org/10.1007/s11881-020-00193-y}

The original version of this article unfortunately contained the following errors. The authors would like to correct the errors with this erratum.

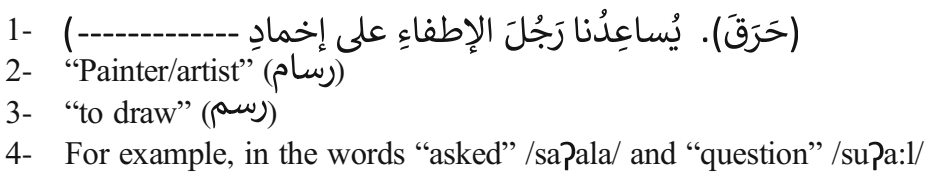

The online version of the original article can be found at https://doi.org/10.1007/s11881-020-00193-y

\section{Sana Tibi}

sana.tibi@cci.fsu.edu

1 School of Communication Science and Disorders, Florida State University, Tallahassee, FL, USA

2 Department of Psychology, Florida State University, Tallahassee, FL, USA

3 Faculty of Education, Queen's University, Kingston, Ontario, Canada 